\title{
Effects of Botulinum Toxin on Reducing the Co-contraction of Antagonists in Birth Brachial Plexus Palsy
}

\author{
Yong Beom Shin, $\mathrm{MD}^{1,2}$, Myung Jun Shin, $\mathrm{MD}^{1,2}$, Jae Hyeok Chang, $\mathrm{MD}^{1,2}$, \\ Young Sun Cha, $\mathrm{MD}^{1,2}$, Hyun-Yoon Ko, $\mathrm{MD}^{1,3}$
}

\begin{abstract}
${ }^{1}$ Department of Rehabilitation Medicine, Pusan National University School of Medicine, Busan; ${ }^{2}$ Biomedical Research Institute Pusan National University Hospital, Busan; ${ }^{3}$ Research Institute for Convergence of Biomedical Science and Technology, Pusan National University Yangsan Hospital, Yangsan, Korea
\end{abstract}

Birth brachial plexus palsy (BBPP) is usually caused by plexus traction during difficult delivery. Although the possibility of complete recovery is relatively high, $5 \%$ to $25 \%$ of BBPP cases result in prolonged and persistent disability. In particular, muscle imbalance and co-contraction around the shoulder and elbow cause abnormal motor performance, osseous deformities, and joint contracture. Physical and occupational therapies have most commonly been used, but these conventional therapeutic strategies have often been inadequate, in managing the residual muscle imbalance and muscle co-contraction. Therefore, we attempted to improve the functional movements, by using botulinum toxin type $\mathrm{A}$, to reduce the abnormal co-contraction of the antagonist muscles.

Keywords Birth brachial plexus palsy, Obstetric brachial plexus injury, Botulinum toxin type A, Brachial plexus neuropathies

\section{INTRODUCTION}

In the treatment of birth brachial plexus palsy (BBPP), conventional methods, such as physical and occupational therapy, remain the main choices. But the misled axons after spontaneous nerve regeneration in BBPP

Received December 26, 2012; Accepted July 18, 2013

Corresponding author: Myung Jun Shin

Department of Rehabilitation Medicine, Pusan National University Hospital, 179 Gudeok-ro, Seo-gu, Busan 602-739, Korea

Tel: +82-51-240-7485, Fax: +82-51-247-7485, E-mail: drshinmj@gmail. com

(c) This is an open-access article distributed under the terms of the Creative Commons Attribution Non-Commercial License (http://creativecommons. org/licenses/by-nc/3.0) which permits unrestricted noncommercial use, distribution, and reproduction in any medium, provided the original work is properly cited.

Copyright $\odot 2014$ by Korean Academy of Rehabilitation Medicine occasionally cause severe muscle co-contractions [1], which may hamper coordinated movements, and disable adequate muscle activities. Although co-contraction of agonist and antagonist usually occurs in central motor disorders, a peripheral nerve lesion, such as BBPP, can affect the development of the nervous system, thereby disrupting the central motor programming [2]. In BBPP, the injured upper limb that does not have normal sensory and motor function has an impact on the infant, in learning the motor control pattern. Therefore, it is important to correct the harmful co-contraction of the muscles as early as possible, for normal motor development.

\section{CASE REPORT}

This study was a prospective case series. Four subjects, 
whose shoulder abduction and elbow flexion function could not be improved by conventional physical and occupational therapies for 6 months, were investigated (Fig. 1). These patients had clinical evidences of major co-contraction in the biceps-triceps and lateral deltoidpectoralis. Appropriate informed consents were obtained from all patients, and the study was approved by the $\mathrm{Pu}$ san National University Hospital Research Ethics Review Board (E2012051). These patients presented with upper plexus involvement (mainly $\mathrm{C} 5-\mathrm{C} 6$ root), and their functional status was determined using the Medical Research Council (MRC) muscle grading system, and the modified Gilbert shoulder evaluation scale.

For the quantification of agonist-antagonist co-contraction during the movement of the affected arm, power spectrum analysis was performed, using the root mean square (RMS) value of motor unit action potentials (Fig. 2). The highest value among three consecutive measurements was chosen. Dantec Counterpoint MK2 machine (Dantec-Medtronic, Skovlunde, Denmark) was used. All scalings were performed prior to the BTA injections, and 1 month after the injections. MRC and modified Gilbert scales were checked prior to the BTA injections, and 6 months after the injections. BTA was injected intramuscularly into the co-contracted antagonist muscles, such as the triceps brachii and pectoralis major. For every 2 $\mathrm{mL}$ of solvent ( $0.9 \%$ sterile saline), the content of botulinum toxin was $5 \mathrm{U}$ in $0.1 \mathrm{~mL}$ solution. We injected 2-3 U/ $\mathrm{kg}$ of Botox (Allergan Inc., Mayo, Ireland), divided for two or three sites of each muscle.

The results of the functional movement and strength of muscles before and after the BTA injections, respectively,

Brachial plexopathy was diagnosed by electrodiagnostic study $(n=5)$

Exclude according to improving function after conventional therapy $(n=11)$

Allocated to intervention $(n=4)$

Lost to follow-up $(n=0)$

Analyzed at 6 months after BTX injection $(n=4)$

Fig. 1. Participant flow chart. BTX, botulinum toxin type A. were determined (Table 1). RMS values of agonist and antagonist were measured before and after the injection, when each of the patients performed elbow flexion and shoulder abduction actions, respectively (Fig. 3 ).

All patients, except for case 2, demonstrated improvement in the modified Gilbert scales. In the case of case 2 , the oldest patient, the RMS value was significantly reduced in the antagonist muscles, but there was no change in the agonist muscles. This result suggested that this patient had no functional improvement.

(A)

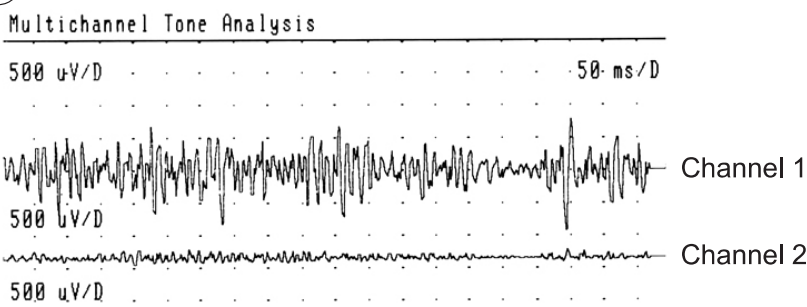

(B)

Multichannel Tone Analysis

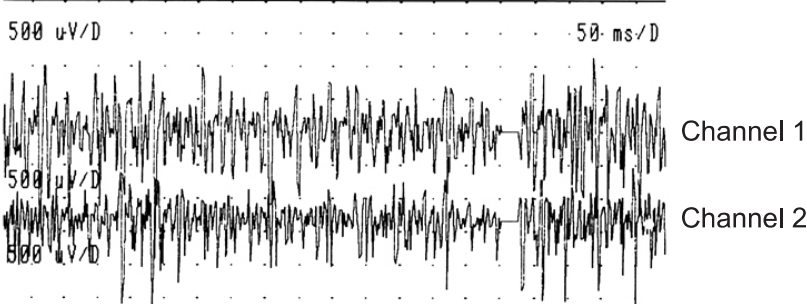

(C)

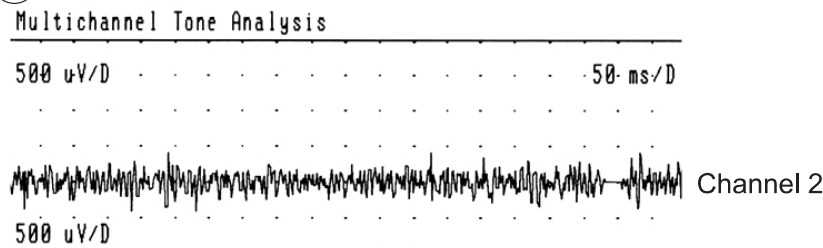

Fig. 2. Two channels surface electromyography of biceps (channel 1) and triceps (channel 2) muscles. (A) Normal contraction pattern of the biceps and triceps muscles during elbow flexion on sound side, before the use of botulinum toxin type A (BTA). (B) The biceps-triceps cocontraction and the pronounced triceps activation during elbow flexion on involved side, before the use of BTA. (C) Reduced triceps co-contraction, 3 weeks after the injection of the BTA in the triceps muscle (only channel 2 visible). 
Table 1. Results of follow-up examinations of patients at before (pre) and 6 months after (post) BTA injection

\begin{tabular}{|c|c|c|c|c|c|c|c|}
\hline \multirow{3}{*}{ Case } & \multirow{3}{*}{ Age at injection } & \multirow{2}{*}{\multicolumn{2}{|c|}{ Modified Gilbert scale }} & \multicolumn{4}{|c|}{ MRC scale $^{\text {a) }}$} \\
\hline & & & & \multicolumn{2}{|c|}{ Biceps brachii } & \multicolumn{2}{|c|}{ Lateral deltoid } \\
\hline & & Pre & Post & Pre & Post & Pre & Post \\
\hline 1 & $4 \mathrm{yr} 10 \mathrm{mo}$ & 2 & 4 & $2-$ & 3 & $2+$ & 3 \\
\hline 2 & 13 yr 5 mo & 2 & 2 & $2-$ & $2-$ & $2+$ & $2+$ \\
\hline 3 & 5 yr 6 mo & 2 & 4 & $2+$ & $3+$ & $2-$ & 3 \\
\hline 4 & $2 \mathrm{yr} 10 \mathrm{mo}$ & 1 & 4 & NT & NT & NT & NT \\
\hline
\end{tabular}

BTA: botulinum toxin type A; MRC, Medical Research Council; NT, not testable.

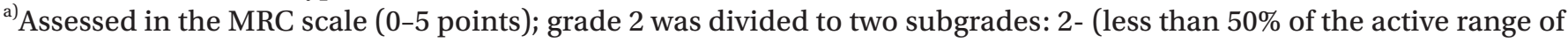
movement) and $2+$ (more than $50 \%$ of the active range of movement).

(A)

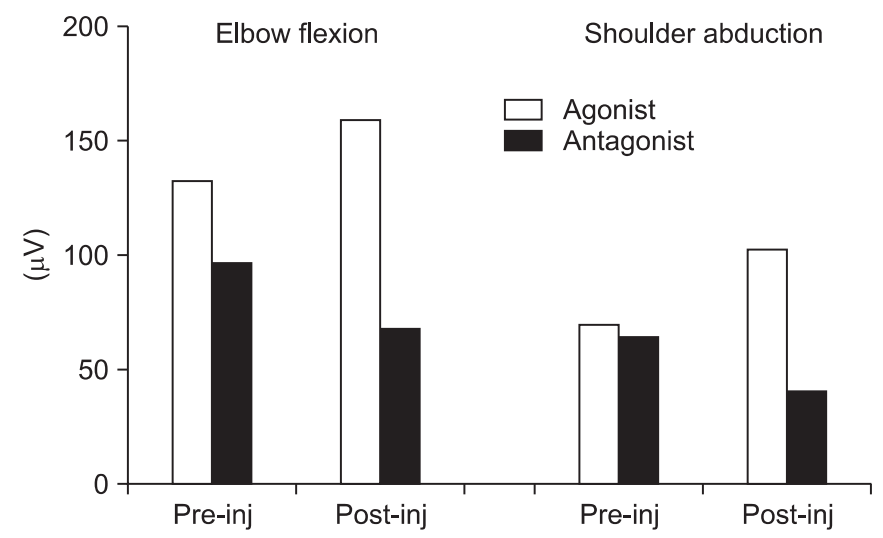

(C)

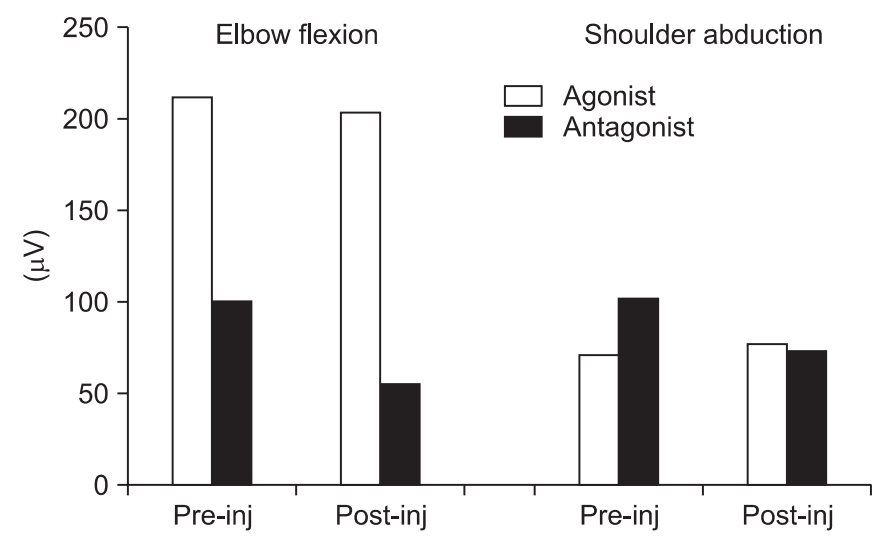

(B)

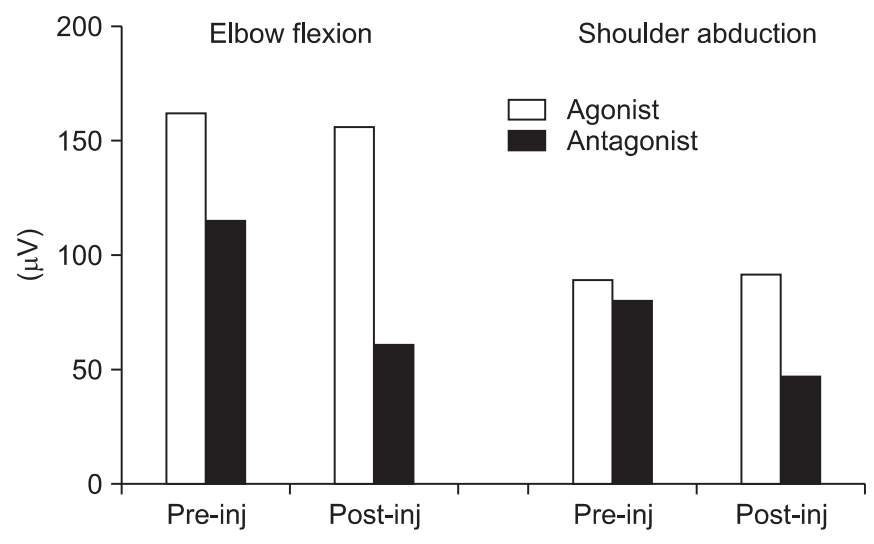

(D)

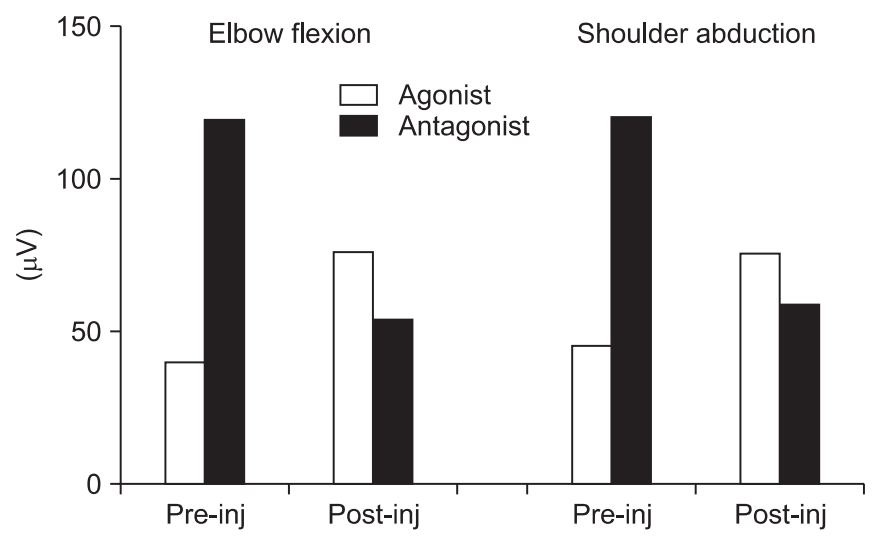

Fig. 3. Root mean square changes after botulinum toxin type A injection. (A) Case 1, (B) case 2, (C) case 3, and (D) case 4.

\section{DISCUSSION}

BBPP is a complication of a difficult delivery, with potentially disabling sequelae. According to previous reports, a majority of patients (around 80\%) recover spontaneously, and only supportive physical therapy was needed $[3,4]$

However, some patients still have difficulty in raising the affected arm above the shoulder height, despite significant neurological and electrophysiological improvement. In other words, injuries may be transient, with nearly complete neurologic recovery, when antigravity 
biceps and deltoid function are usually observed by age 2 months. Or they may result in a permanent flail arm, which is usually associated with a complete plexus lesion, and the avulsion of the cervical spinal nerve roots. Depending on the medical center, recommendations typically involve plexus exploration and grafting, during the period from 3 to 9 months following birth [5]. In our cases of late BBPP, microsurgical intervention was no longer practical, and palliative surgery could be recommended [3].

After age 2 to 3, patients with BBPP whose nerves are not completely recovered will have residual deficits [6]. These deficits often lead to muscle imbalance, and cocontraction. Co-contraction of antagonist muscles can be explained with two different mechanisms. The first, developmental apraxia, is a central motor program deficiency secondary to poor sensory-motor stimulation of the brain, during a critical period of neuronal maturation [2]. The second is the consequences of axonal repair, with axonal splitting and aberrant nerve outgrowth [7]. These situations can eventually be changed by neuronal plasticity [1].

Generally, the intended effect of BTA is to reduce muscle tone, and to force the restoration of the passive range of motion and joint alignment [3]. There may also be an effect on the central nervous system in children with BBPP [8]. Several studies showed that therapeutic weakening of overactive muscles provides a window of opportunity for the child to regain improved control of these reinnervated muscles, and work towards a normal synergistic pattern, of agonist contraction with antagonist relaxation. These studies are similar to our cases, in that children responded very quickly to BTA injection (within 1-2 weeks), with maintenance of change for 4 months and longer [4]. In our cases, treatment of the co-contracting muscle with BTA injection aimed to weaken the antagonist, and to improve the function of the agonist. Children in 2 to 5 years of age demonstrated functional improvements in the modified Gilbert scales, which were improved for 6 months. In particular, the youngest patient showed the greatest functional improvement. The reason for this long lasting effect is as yet unknown, and the authors believe that it is related to the enhancement of opportunity for children to learn more efficient, functional synergistic movement patterns, and to have an effect on changes at a central programming level [9]. To the best of the authors' knowledge, this is the first report of the combination of BTA injection into the co-contracted antagonist triceps brachii and pectoralis major muscles, including objective RMS values of motor unit action potentials.

In the oldest patient case 2, the RMS value was significantly reduced in the antagonist muscle, but there was no functional improvement. Before BTA injection, the only case 2 patient had limited passive range of motion (PROM) in shoulder abduction $\left(110^{\circ}-0^{\circ}-90^{\circ}\right)$, and elbow extension $\left(0^{\circ}-25^{\circ}-150^{\circ}\right)$, but the other three patients did not. We believed that such limited PROM and joint contracture caused muscle shortness and decreased muscle power; therefore, BTA injection did not affect the functional movement. In view of case 2 and other literatures, patients older than 6 years of age with BBPP may be treated with BTA, before being affected by the limitations of PROM, or with a surgical means, on osseous deformities and joint contracture, for functional improvement [10].

The results in our series suggest that local BTA injections can be beneficial for controlling the harmful cocontraction of antagonist muscles in children with BBPP, except for those with a considerable PROM limitation. But, the number of cases was too small for generalization.

\section{CONFLICT OF INTEREST}

No potential conflict of interest relevant to this article was reported.

\section{ACKNOWLEDGMENTS}

This work was supported by a clinical research grant from Pusan National University Hospital in 2013.

\section{REFERENCES}

1. van Dijk JG, Pondaag W, Malessy MJ. Obstetric lesions of the brachial plexus. Muscle Nerve 2001;24:1451-61.

2. Brown T, Cupido C, Scarfone H, Pape K, Galea V, McComas A. Developmental apraxia arising from neonatal brachial plexus palsy. Neurology 2000;55:24-30.

3. Vekris MD, Lykissas MG, Beris AE, Manoudis G, Vekris AD, Soucacos PN. Management of obstetrical brachial plexus palsy with early plexus microreconstruction 
and late muscle transfers. Microsurgery 2008;28:25261.

4. DeMatteo C, Bain JR, Galea V, Gjertsen D. Botulinum toxin as an adjunct to motor learning therapy and surgery for obstetrical brachial plexus injury. Dev Med Child Neurol 2006;48:245-52.

5. Pearl ML. Shoulder problems in children with brachial plexus birth palsy: evaluation and management. J Am Acad Orthop Surg 2009;17:242-54.

6. Strombeck C, Krumlinde-Sundholm L, Forssberg H. Functional outcome at 5 years in children with obstetrical brachial plexus palsy with and without microsurgical reconstruction. Dev Med Child Neurol 2000;42:148-57.

7. van Dijk JG, Pondaag W, Malessy MJ. Botulinum toxin and the pathophysiology of obstetric brachial plexus lesions. Dev Med Child Neurol 2007;49:318-9.

8. Intiso D, Basciani M. Botulinum toxin use in neurorehabilitation to treat obstetrical plexus palsy and sialorrhea following neurological diseases: a review. NeuroRehabilitation 2012;31:117-29.

9. Heise CO, Goncalves LR, Barbosa ER, Gherpelli JL. Botulinum toxin for treatment of cocontractions related to obstetrical brachial plexopathy. Arq Neuropsiquiatr 2005;63:588-91.

10. Chuang DC, Ma HS, Borud LJ, Chen HC. Surgical strategy for improving forearm and hand function in late obstetric brachial plexus palsy. Plast Reconstr Surg 2002;109:1934-46. 